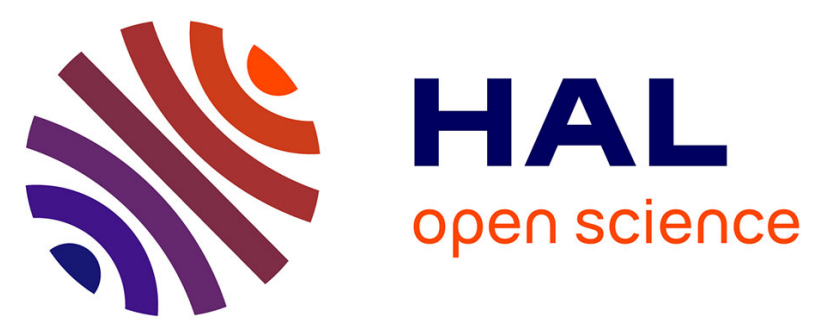

\title{
A first comparison of Cosmo-Skymed and TerraSAR-X data over Chamonix Mont-Blanc test-site
}

\author{
Jean-Marie Nicolas, Emmanuel Trouvé, Renaud Fallourd, Flavien Vernier,
} Florence Tupin, Olivier Harant, Michel Gay, Luc Moreau

\section{- To cite this version:}

Jean-Marie Nicolas, Emmanuel Trouvé, Renaud Fallourd, Flavien Vernier, Florence Tupin, et al.. A first comparison of Cosmo-Skymed and TerraSAR-X data over Chamonix Mont-Blanc test-site. IGARSS 2012 - IEEE International Geoscience and Remote Sensing Symposium, Jul 2012, Munich, Germany. pp.4141. hal-00797185

\section{HAL Id: hal-00797185 \\ https://hal.science/hal-00797185}

Submitted on 5 Mar 2013

HAL is a multi-disciplinary open access archive for the deposit and dissemination of scientific research documents, whether they are published or not. The documents may come from teaching and research institutions in France or abroad, or from public or private research centers.
L'archive ouverte pluridisciplinaire HAL, est destinée au dépôt et à la diffusion de documents scientifiques de niveau recherche, publiés ou non, émanant des établissements d'enseignement et de recherche français ou étrangers, des laboratoires publics ou privés. 


\title{
A FIRST COMPARISON OF COSMO-SKYMED AND TERRASAR-X DATA OVER CHAMONIX MONT-BLANC TEST-SITE
}

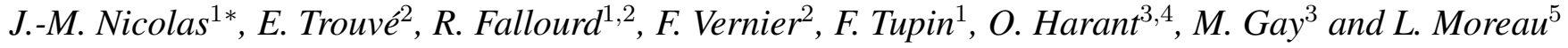 \\ 1: Laboratoire de Traitement et Communication de l'Information, \\ CNRS, Télécom ParisTech, 46 rue Barrault, 75013 Paris, France \\ 2: Laboratoire d'Informatique, Systèmes, Traitement de l'Information et de la Connaissance \\ Université de Savoie, Polytech Annecy-Chambéry, BP 80439, F-74944 Annecy-le-Vieux Cedex, France \\ 3: GIPSA-lab, CNRS INPG - 961, Rue de la Houille Blanche - BP 46 - 38402 Saint-Martin-d'Hères, France \\ ${ }^{4}$ : IETR, SAPHIR Team, University of Rennes 1, Bat. 11D, 263 Av. du G. Leclerc 35042 Rennes, France \\ ${ }^{5}$ : EDYTEM, CNRS, Université de Savoie, F-73376, Le Bourget du Lac, France.
}

\begin{abstract}
This paper presents the first results obtained with satellite image time series (SITS) acquired by Cosmo-SkyMed (CSK) over the Chamonix Mont-Blanc test-site. A CSK SITS made of 39 images is merged with a TerraSAR-X SITS made of 26 images by using the orbital information and co-registration tools developed in the EFIDIR project. The results are illustrated by the computation of speckle-free images by temporal averaging, by the generation and comparison of topographic interferograms and by the measure of glacier displacement fields by amplitude correlation.
\end{abstract}

Index Terms - SAR images time series, Cosmo-SkyMed, TerraSAR-X, interferometry, correlation, glaciers

\section{INTRODUCTION}

Chamonix Mont-Blanc has become one of the experimental test site to demonstrate the potential of Earth Observation data for Alpine glacier monitoring. Various sources of information have been used and merged to measure the evolution of the glacier surface (elevation, displacement fields, classifications...): spaceborne optical images (SPOT) [1], airborne photography and the first generation of SAR spaceborne data (ERS) [2], airborne SAR data acquired by the DLR in 2006 and 2007 (E-SAR) [3]... This test site has also been proposed by the EFIDIR project teams (http://www.efidir.fr) in response to the Announcements of Opportunities issued from the different space agencies for the launch of the new generation SAR satellites. The EFIDIR project objective is to develop an open platform of archival storage and of processing, fitted on one hand to SAR data specificity and, on the other hand, to large time series of SAR images from which ground motion measures are extracted. The first results obtained with High Resolution data (TerraSAR-X) [4] or fully

\footnotetext{
*jean-marie.nicolas@telecom-paristech.fr
}

polarimetric data (Radarsat-2) [5] show an increased potential in terms of measurement of displacement fields and analysis of the temporal evolutions [6].

In this paper, we present the first results obtained on this test site with Cosmo-SkyMed (CSK) stripmap data (project 2145, "Monitoring glacier activity by combined interferometry and Single Look Complex image processing"). A set of 39 images has been acquired in ascending passes between March 2009 and December 2011. The aim of this first analysis is to provide some comparisons with a set of 26 TerraSAR-X (TSX) stripmap data acquired in ascending passes between May 2009 and September 2011, with a slightly different incidence angle: $34^{\circ}$ for CSK and $44^{\circ}$ for TSX. Despite this difference and its geometrical consequences, we illustrate how such satellite image time series (SITS) can be combined to increase the repetitivity of space-borne SAR observations for the monitoring of fast changing geophysical features such as Alpine glaciers. We first describe the co-registration technique developed to built the time series by using only the orbital information and how it can be used for either TSX or CSK data stacking, and even for direct inter-sensor coregistration to obtain a stack of 65 images mixing CSK and TSX data. We then illustrate the potential of these time series with early results such as speckle-free images, interferometric fringes in coherent areas and displacement measurement by amplitude correlation over glaciers.

\section{CO-REGISTRATION OF THE CSK-TSX DATA SET}

Co-registration of SAR images from repeated orbits is a well known task with some specific tools often developed for interferometric applications which requires sub-pixel accuracy. Those developed for the first generation of SAR satellites are usually based on similarity measures to derive geometrical transforms necessary to re-sample the slave image over the master one, and then "substract" the orbital and topographi- 
cal fringes in a second stage. The increased accuracy of the state vectors provided with the new generation SAR satellites such as TSX and CSK and their higher resolution allows different approaches to be experimented.

In this paper, we perform this resampling by using directly the meta information provided in the TSX xml files or CSK H5 files, without using similarity measurements which are dependant on the image content (textured or homogeneous areas), and very sensitive to surface changes (snow fall, seasonal variations...) and variations of the incidence angles in the case of images acquired from different tracks or from two different sensors such as CSK and TSX. Moreover, by using the pure geometric information associated to the radar principle and the SAR systems (antenna positions, range and azimuth sampling...), we can avoid mixing the offset due to the baseline with the sought-after information: the offset due to the ground surface displacement.

Then, depending on the topography of the scene and on the availability of an accurate DEM, we can implement this approach with or without using a DEM. Without DEM (as illustrated in the rest of this paper), only a constant "mean" altitude is introduced. The results presented in the following section show that this can be sufficient for a local scale observation as it is often the case for ground motion due to land instability, urban subsidence or mountain glaciers. This makes the processing rather straightforward and avoid the requirement of a DEM which can also be a source of errors. In the case of large scale observation, as for seismic deformations, the DEM information can be introduced by computing for each ground points the difference of the distance to the antenna, and projecting this information on the Master image grid as proposed in radar-coding tools [7].

\section{EXPERIMENTAL RESULTS}

\subsection{CSK and TSX Chamonix Mont-Blanc data set}

The co-registration technique presented in the previous section has been applied to a large data set made of $65 \mathrm{X}$-band SAR images acquired in ascending passes over Chamonix Mont-Blanc test-site, with 39 Cosmo-SkyMed images and 26 TerraSAR-X images. This technique initially devoted to TSX images has been used to register CSK data without any adaptation (except a slight remaining translation between the two sensors). The main characteristics of the CSK and TSX time series are recalled in Table 1.

This data set covers several well known glaciers of the Mont-Blanc massif, the city of Chamonix and several ski stations of the valley. The Argentière glacier is one of the most studied glaciers in the Chamonix Mont-Blanc valley because of the long history of scientific experimentations and measurements performed on its surface and under the glacier thanks to galleries built to collect water for hydro-electricity.

Figure 1 illustrates the Argentière and Mer-de-Glace

\begin{tabular}{|l|c|c|}
\hline & CSK & TSX \\
\hline Satellite height & $629 \mathrm{~km}$ & $515 \mathrm{~km}$ \\
Beam ID & H4-05 & SSC_SM_S \\
Polarisation & $\mathrm{HH}$ & $\mathrm{HH}$ \\
Mean incidence angle & 33.98 & 44.52 \\
\hline PRF & $3330 . \mathrm{MHz}$ & $3358 \mathrm{MHz}$ \\
Sampling frequency & $127.5 \mathrm{MHz}$ & $109.9 \mathrm{MHz}$ \\
\hline Slant/ground range spacing & $1.17 / 2.11 \mathrm{~m}$ & $1.36 / 1.94 \mathrm{~m}$ \\
Azimut spacing & $2.07 \mathrm{~m}$ & $1.98 \mathrm{~m}$ \\
\hline Nb. acquisitions (2009) & 8 & 13 \\
Nb. acquisitions (2010) & 16 & 0 \\
Nb. acquisitions (2011) & 15 & 13 \\
\hline Acquisition hours & morning & afternoon \\
Baselines (mean, max) & $-1458,1472$ & $-568,526$ \\
\hline
\end{tabular}

Table 1. CSK and TSX data set acquired in ascending passes over Chamonix Mont-Blanc test-site

glaciers visibility on CSK and TSX data. Even if the CSK local incidence angle is lower than with TSX, creating more noticeable foldover artefacts, it is possible to analyse the totality of Argentière glacier with this CSK and TSX dataset.

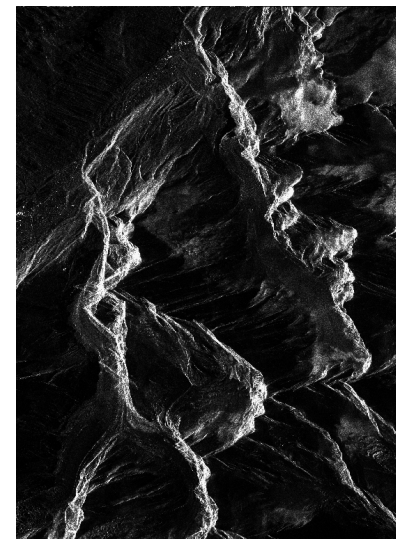

CSK (4560x6360 pix.)

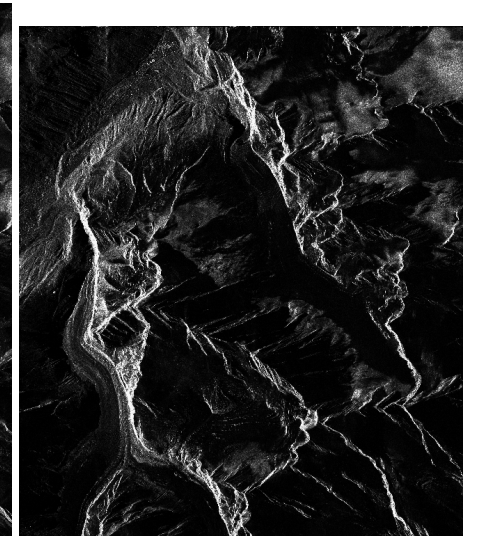

TSX (5120x5850 pix.)
Fig. 1. CSK and TSX acquisitions over Argentière and Merde-Glace glaciers on May 5, 2011 in their initial geometry

\subsection{Temporal averaging}

To illustrate the performance of the direct co-registration technique and the potential of the resulting CSK and TSX stacks, we first propose to derive speckle-free images by computing the temporal geometrical mean. The two time series are co-registered independently, then for each stack, the magnitudes are averaged along the temporal axis with a geometrical mean which seems to be pertinent in this temporal framework [8].

The results obtained with the CSK and the TSX time series are illustrated in Figure 2 on the parking area of the "Grand-Montet" cable car. The results can be considered as speckle-free images obtained without losing spatial resolution. Thanks to this averaging, several features become 


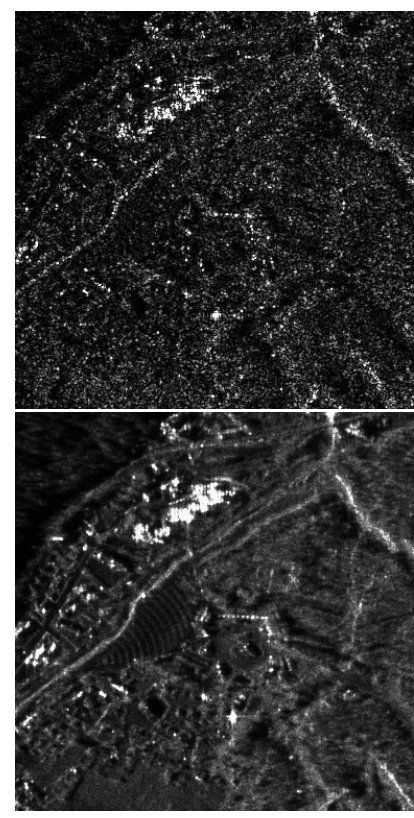

CSK

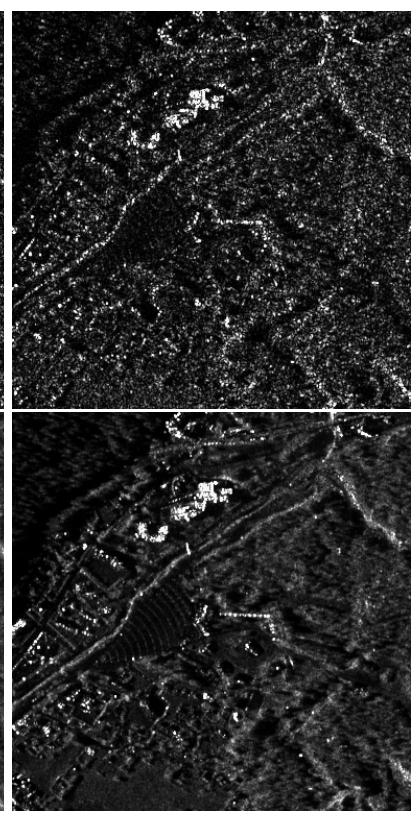

TSX
Fig. 2. Speckle removal obtained by temporal averaging of 39 CSK images and 26 TSX images acquired over Chamonix Mont-Blanc. 382x382 pixels sub-image of the "GrandMontet" cable car parking area.

clearly visible like the curves of the parking separations, the aligned strong scattered of skiing facilities...

\subsection{Interferograms}

Although these data have not been acquired in interferometric mode, it is possible to generate interferograms from the coregistered SLC images. The results obtained with a CSK pair and a TSX pair acquired in September 2009 are illustrated in Figure 3. In both cases, the coherence is lost over the glacier due to important surface changes within 16 days (CSK) or 11 days (TSX). On the lateral moraines, the coherence is strong enough to preserve the phase information, with a lower level in the CSK interferograms mostly due to the larger temporal and spatial baselines.

Since the orbital fringes have been removed in the coregistration step, the phase rotation observed in Figure 3 corresponds to topographic fringes and is proportional to the perpendicular baseline $B_{\perp}$. For these two interferograms, the ratio of the perpendicular baselines is equal to 3 , which allows a direct comparison of the fringe patterns as illustrated in Figure 4. For each TSX fringe displayed in gray levels, one can observe three CSK fringes displayed in color.

\subsection{A first test of displacement measurement}

In the EFIDIR project, a method based on the Zero-mean Normalized Cross Correlation (ZNCC) allows glacier displacement to be estimated on cracked glaciers [4]. This method has been applied on the co-registered CSK - TSX SITS on the

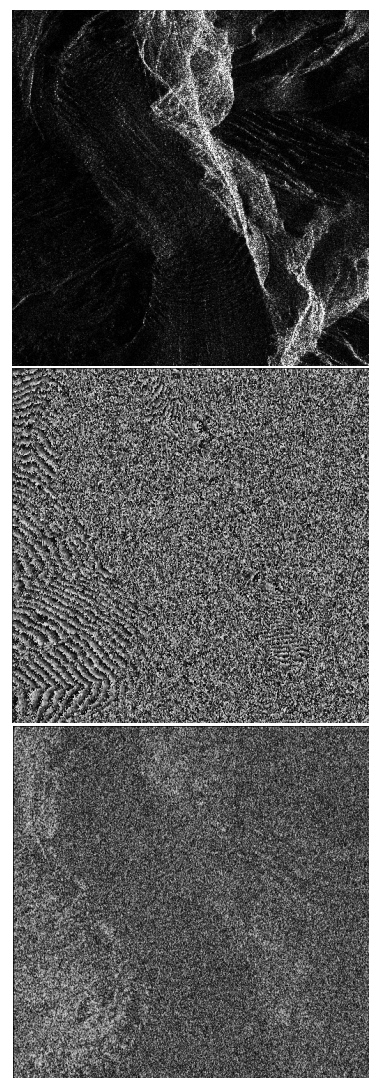

CSK: $2009 / 09 / 04-20, B_{\perp}=399 \mathrm{~m}$

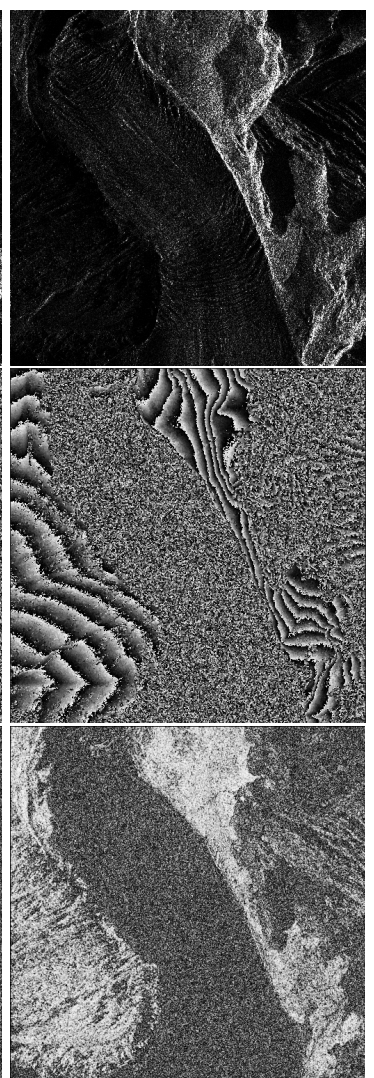

TSX: 2009/09/18-29, $B_{\perp}=133 \mathrm{~m}$
Fig. 3. Amplitude, phase and coherence over a part of Argentière glacier after time series co-registration $(1024 \times 1024$ pixels area, $3 \times 3$ averaging)

cracked area illustrated in Figure 3. The results presented in Figure 5-a) illustrate the ZNCC level obtained for the best matching with $51 \times 51$ pixels windows. The range and azimuth offsets are converted in meter/day and illustrated together with the 2D displacement magnitude in Figure 5-b)-c) and d) respectively. The glacier displacement in the North direction is clearly observed whereas the LOS displacement and the azimuth displacement on motion-free areas are close to zero. Both results are consistent, with less noise (wrong matching) with the TSX data which are more correlated.

\section{CONCLUSIONS}

After this positive experiment on combining CSK and TSX time series, the EFIDIR teams aim to develop automatic tools to analyse long SAR SITS. On the Chamonix MontBlanc glaciers, further research includes the determination of displacement charts with long time series of CSK data corresponding to 2010 and 2011 summers combined with TerraSAR-X time series from 2009 to 2011. By this way, a global analysis of these glaciers during several years can be provided to glaciologists to complement spatially and temporally the in-situ measurements. 


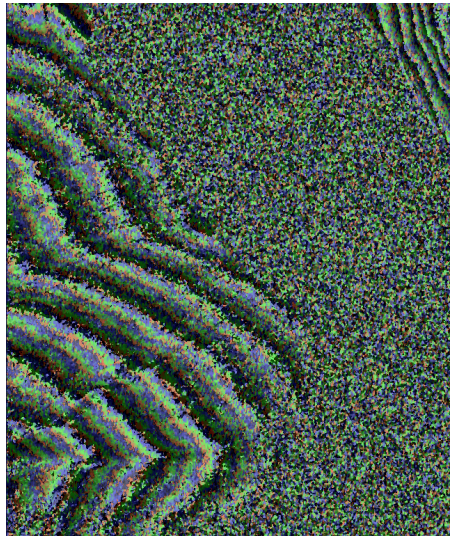

Fig. 4. Composition of the TSX (in gray) and CSK (in color) topographic fringes, on a 540x640-pixels area (lower left corner of Figure 3.

\section{ACKNOWLEDGMENTS}

This work was supported by the EFIDIR project(ANR-07-MDCO004, http://www.efidir.fr), granted by the French National Research Agency (ANR). The authors wish to thank the German Space Agency (DLR) for providing the TerraSAR-X data (Project MTH0232) and the Italian Space Agency (ASI) for providing the CSK data (Project 2145).

\section{REFERENCES}

[1] E. Berthier, H. Vadon, D. Baratoux, Y. Arnaud, C. Vincent, K.L. Feigl, F. Rémy, and B. Legrésy. Mountain glaciers surface motion derived from satellite optical imagery. Remote Sensing Environ., 95(1):14-28, 2005.

[2] E. Trouvé, G. Vasile, M. Gay, L. Bombrun, P. Grussenmeyer, T. Landes, J.M. Nicolas, P. Bolon, I. Petillot, A. Julea, L. Valet, J. Chanussot, and M. Koehl. Combining airborne photographs and spaceborne SAR data to monitor temperate glaciers. Potentials and limits. IEEE Transactions on Geoscience and Remote Sensing, 45(4):905-923, 2007.

[3] T. Landes, M. Gay, E. Trouvé, J.-M. Nicolas, L. Bombrun, G. Vasile, and I. Hajnsek. Monitoring temperate glaciers by high resolution Pol-InSAR data: first analysis of Argentière E-SAR acquisitions and in-situ measurements. In Proc. of the IEEE International Geoscience and Remote Sensing Symposium, IGARSS'07, pages 184 - 187, Barcelona, Spain, 2007.

[4] Renaud Fallourd, Olivier Harant, Emmanuel Trouvé, Jean-Marie Nicolas, Michel Gay, Andrea Walpersdorf, Jean-Louis Mugnier, Jonathan Serafini, Diana Rosu, Lionel Bombrun, Gabriel Vasile, Nathalie Cotte, Flavien Vernier, Florence Tupin, Luc Moreau, and Philippe Bolon. Monitoring Temperate Glacier Displacement by Multi-Temporal TerraSAR$\mathrm{X}$ Images and Continuous GPS Measurements. IEEE Journal of Selected Topics in Applied Earth Observations and Remote Sensing (JSTARS), 4(2):372-386, 2011

[5] O. Harant, L. Bombrun, G. Vasile, L. Ferro-Famil, and M. Gay. Displacement estimation by maximum likelihood texture tracking. IEEE Journal of Selected Topics in Signal Processing, 5(3):398-407, 2011.

[6] A. Julea, F. Ledo, N. Méger, E. Trouvé, P. Bolon, C. Rigotti, R. Fallourd, J.-M. Nicolas, G. Vasile, and O. Harant. PolSAR Radarsat-2 satellite image time series mining over the Chamonix Mont-Blanc test site. In Proc. of the IEEE International Geoscience and Remote Sensing Symposium, IGARSS'2011, pages 1191 - 1194, Vancouver, Canada, 2011.

[7] I. Pétillot, E. Trouvé, P. Bolon, A. Julea, Y. Yan, M. Gay, and J.M. Vanpé. Radar-Coding and Geocoding Lookup Tables for the Fusion of GIS and Sar Data in Mountain Areas. IEEE Geoscience and Remote Sensing Letters, 7(2):309-313, 2010. a)
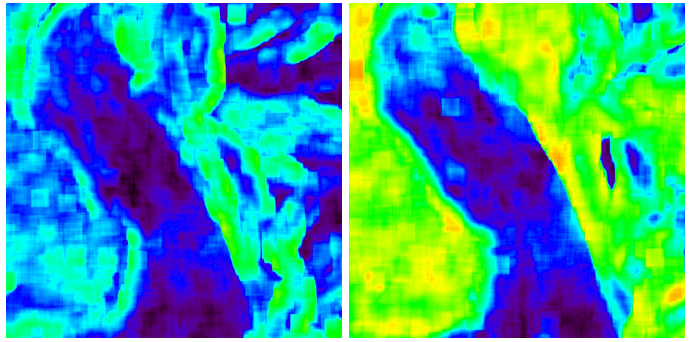

b)
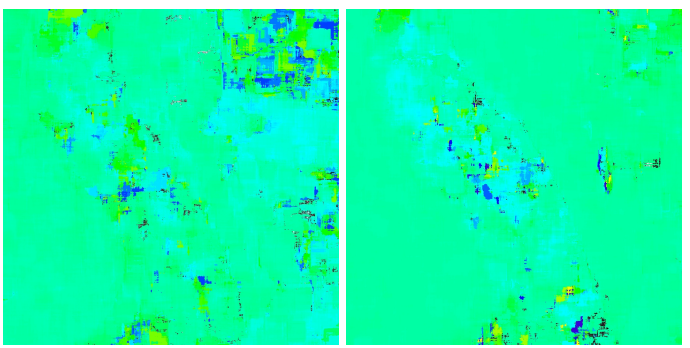

c)
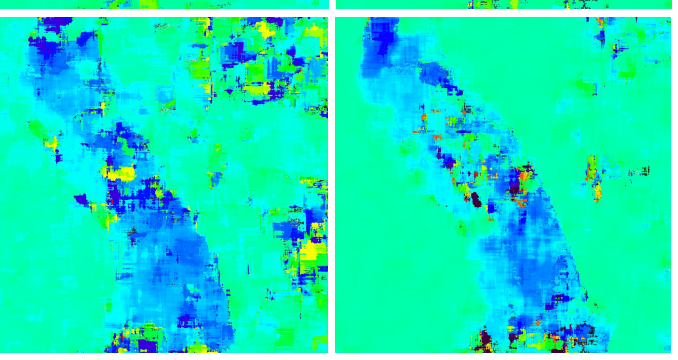

d)
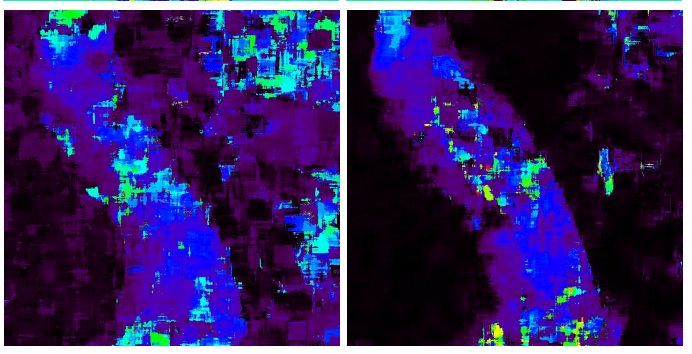

CSK: $2009 / 09 / 04-20, B_{\perp}=399 \mathrm{~m}$

TSX: 2009/09/18-29, $B_{\perp}=133 \mathrm{~m}$

Fig. 5. 2D displacement measured by amplitude correlation on the CSK and TSX image pairs illustrated in Figure 3; a) correlation level $[0,1]$, b)-c) range and azimuth $[-1,1]$ $\mathrm{m} /$ day, d) displacement magnitude $[0,1] \mathrm{m} /$ day, with rainbow colormap scaled over the $[\min , \max ]$ intervals;

[8] G. Quin, B. Pinel-Puyssegur, and J.-M. Nicolas. Comparison of harmonic, geometric and arithmetic means for change detection in SAR time series. In EUSAR 2012 - 9th European Conference on Synthetic Aperture Radar, Nuremberg, Germany, April 2012. 